\title{
A MALE PATIENT WITH NET-LIKE HYPERPIGMENTATION ON THE LOWER LIMBS
}

Shyamashis Das, Achintya Narayan Ray, Pasang L. Sherpa, Bapi Lal Bala

1. Assistant Professor. Department of Rheumatology, North Bengal Medical College, Darjeeling, India.

2. Associate Professor. Department of Medicine, North Bengal Medical College, Darjeeling, India.

3. Assistant Professor. Department of Medicine, North Bengal Medical College, Darjeeling, India.

4. Clinical Tutor of Medicine,

\section{CORRESPONDING AUTHOR:}

Dr. Shyamashis Das.

Flat no. - A3, D-72,

Ramgarh, Kolkata - 70047, India.

E-mail: shyamashis@yahoo.co.in

Ph: 00919433654275.

A 35-year-old male presented with complaints of jaundice and persistent epigastric pain for two weeks. He also complained of net-like hyperpigmentation on both the legs that developed over last three months. He used to drink alcohol frequently for last 5-6 years. He was normotensive and non-diabetic. He had no history of fever, arthralgia or oral ulcers. Examination revealed mild epigastric tenderness with tender hepatomegaly. On the medial aspects of both legs he had reddish-brown pigmentation in reticulated pattern (Figure 1). The lesion was non-tender and there was no ulceration or scaling on the skin. Laboratory evaluation showed mild leucocytosis, Serum alanine aminotransferase (ALT) $180 \mathrm{U} / \mathrm{L}$, aspartate aminotransferase (AST) $256 \mathrm{U} / \mathrm{L}$, Alkaline Phosphatase $110 \mathrm{IU} / \mathrm{L}$, total bilirubin $4.5 \mathrm{mg} / \mathrm{dL}$ and normal serum lipase. Blood borne virus screening (namely, HBsAg and antibodies to HCV and HIV) were negative. Lupus anticoagulant and anti-cardiolipin antibody were also negative. Ultrasound abdomen revealed hepatomegaly with fatty changes in liver, normal portal and hepatic veins with normal pattern of blood flow. He was diagnosed to have alcoholic hepatitis. Upon further questioning, it was revealed that he had a developed a habit to sit next to an earthen oven with a fire in it for several hours during winter months.

\section{Differential diagnosis:}

1. Erythema ab igne

2. Livedo reticularis

The history and physical appearance were consistent with a diagnosis of erythema ab igne. Erythema ab igne (EAI) is an uncommon skin lesion caused by repeated and prolonged exposure to thermal (or infra red) radiation (in the range of $43-47^{\circ} \mathrm{C}$ ) that is not sufficient to produce a burn [1]. In acute stage, it looks like erythematous interlacing bands, which gradually darkens on chronic exposure. The diagnosis of EAI is clinical. Various types of heat sources have been reported to cause it, including stove, heating pads, hot water bottles, car heaters, electric space heaters, footbath with Chinese herbal remedies [2] and laptop computers [1]. Removal of the heat source often results in resolution of the lesion [3]. Although EAI has good prognosis, chronic EAI may have an increased risk of carcinoma (Squamous-cell carcinoma and Merkel-cell carcinoma) [4]. 
Livedo reticularis which has been associated with antiphospholipid antibody syndrome, systemic lupus erythematosus, polyarteritis nodosa, cryoglobulinemia etc. resembles EAI because of erythematous reticular pattern but systemic manifestations of these diseases are typically absent in EAI [5].

Author information: Shyamashis Das, Assistant Professor of Rheumatology; Achintya Narayan Ray, Associate Professor of Medicine; Pasang L Sherpa, Assistant Professor of Medicine; Bapi Lal Bala, Clinical Tutor of medicine; North Bengal Medical College, Darjeeling, India.

Correspondence: Dr. Shyamashis Das. E-mail: Shyamashis@yahoo.co.in. Address: Flat no. D 602, Rail Bihar, New Town, Rajarhat, Kolkata - 700156.

\section{REFERENCES:}

1. Arnold AW, Itin PH. Laptop computer-induced erythema ab igne in a child and review of the literature. Pediatrics 2010;126:e1227-30.

2. Chen JF, Liu YC, Chen YF, Chiang CP, Wang WM. Erythema Ab igne after footbath with Chinese herbal remedies. J Chin Med Assoc 2011;74:51-3.

3. Chan CC, Chiu HC. Images in clinical medicine. Erythema ab igne. N Engl J Med 2007;356:e8.

4. Miller K, Hunt R, Chu, Shane M, Jennifer S. Erythema ab igne. Dermatol Online J. 2011; 17(10): 28.

5. Ryan RR, Philip RC, Floyd WR, James MG. Erythema ab igne mimicking livedo reticularis. Int J Dermatol 2010; 49(11): 1314-1317.

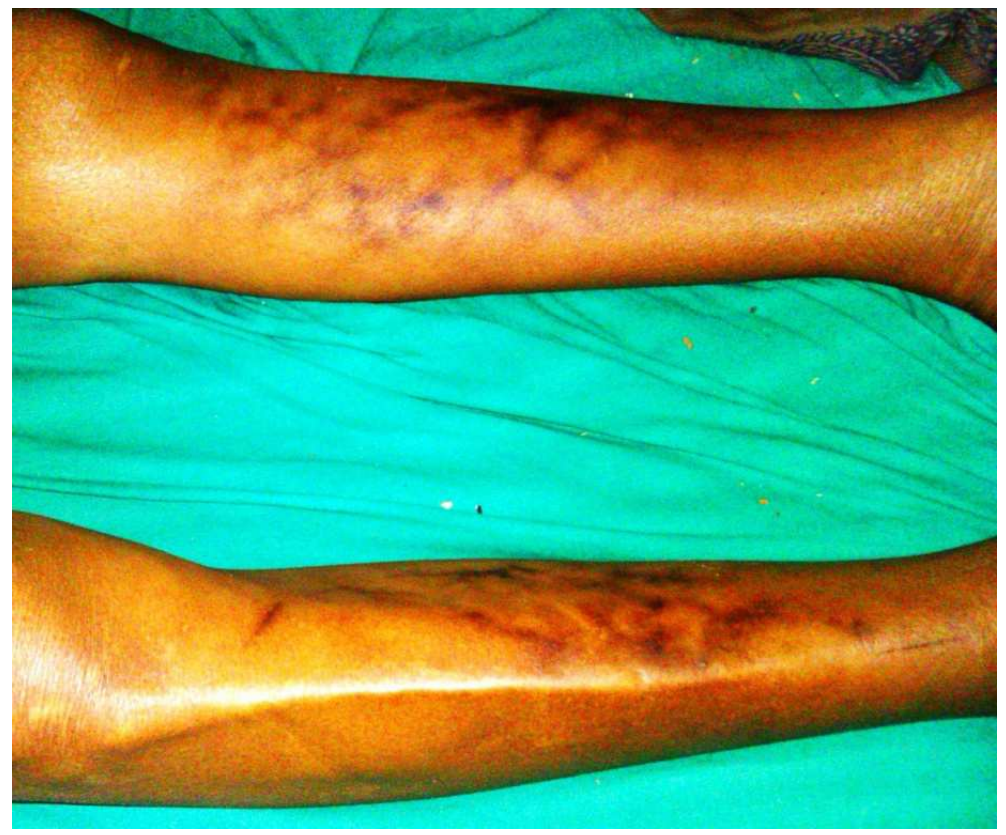

Figure 1. Erythema ab igne in a patient with alcoholic liver disease 